\title{
La construcción del espacio psíquico representacional frente a lo inconvertible de la violencia: Identidad, política y alteridad
}

\author{
A construção do espaco psíquico representacional diante \\ da violência inconvertivel: Identidade, politica e alteridade
}

DANIEL JOFRÉ

ALEJANDRO BILBAO ${ }^{b}$

\section{Resumen}

El artículo busca profundizar en las elaboraciones de Freud respecto de la agresividad y la inconvertibilidad de la violencia, con el objeto de indagar en los posibles aportes que la perspectiva psicoanalítica puede realizar frente a los problemas sociopolíticos contemporáneos. Este trabajo se detiene en las problemáticas referidas a la naturalización de las identidades, la radicalización de las retóricas comunitarias y los escenarios de exclusión. Sostiene, en este sentido, la importancia de los procesos sublimatorios en el trabajo de diferimiento frente al empuje pulsional.

Palabras clave: Agresividad. Violencia. Identidad. Exclusión. Sociedades contemporáneas.

\section{Resumen}

O artigo busca aprofundar-se nas elaborações de Freud a respeito da agressividade e a inconversibilidade da violência, com o objetivo de indagar as possíveis contribuições que a perspectiva psicanalítica pode realizar diante dos problemas sócio-políticos contemporâneos. Este trabalho se detém nas problemáticas referidas à naturalização das identidades, a

\footnotetext{
a Universidad Austral de Chile, Puerto Montt, Región de los Lagos, Chile. Doutor, e-mail: daniel.jofre@uach.cl

b Universidad de los Lagos, Osorno, Región de los Lagos, Chile. Doutor, e-mail: bilbao1231@hotmail.com
} 
radicalização das retóricas comunitárias e os cenários de exclusão. Sustenta, neste sentido, a importância dos processos sublimatórios no trabalho de diferimento diante do estímulo pulsional.

Palavras-chave: Agressividade. Vioência. Identidade. Exclusão. Sociedades contemporâneas.

\section{Abstract}

The article pursues to deepen in Freud's work about aggressiveness and the inconvertibility of violence. The objective is to inquire inside the possible contributions that the psychoanalytic perspective can bring against sociopolitical issues in the contemporaneity. This work goes into the issues related to the naturalization process, the radicalization of the community rhetoric and exclusion scenarios. It sustains, in this sense, the importance of the sublimatory processes in the deferral work against the drive impulse.

Keywords: Aggression. Violence. Identity. Exclusión. Current societies.

"YY qué clase de reacción de la vida anímica esperaríamos frente a esa intrusión? De todas partes es movilizada la energía de investidura a fin de crear, en el entorno del punto de intrusión, una investidura energética de nivel correspondiente. Se produce una enorme "contrainvestidura" en favor de la cual se empobrecen todos los otros sistemas psíquicos, de suerte que el resultado es una extensa parálisis o rebajamiento de cualquier otra operación psíquica" (Freud, Más allá del principio del placer, 29-30).

\section{Introducción}

Pese a la ausencia en el pensamiento de Freud de una tesis explícita sobre la vinculación entre agresividad, violencia y política, es posible señalar la existencia dentro de los postulados psicoanalíticos, de un discernimiento decidido respecto de las condiciones con que el viviente humano, encuentra en sus condiciones representacionales, la posibilidad de construir ligazones psíquicas y desligazones entre los impulsos provenientes de lo corporal y el campo de mediaciones que se organizan a partir del encuentro con el Otro. Siendo, pues, en este espacio en donde se movilizan los diversos destinos pulsionales y se experimenta la agresividad hacia la propia persona o hacia el otro, como resultados de los juegos de fuerza y de las condiciones dinámicas que estructuran el psiquismo. El espacio 
sostenido por estas mediaciones entre lo psíquico, lo pulsional y el mundo exterior, también ampara los posicionamientos subjetivos frente a las organizaciones institucionales que delimitan el campo de lo político, garantizando tanto la construcción del espacio interhumano que mediatiza lo legal afrontando la cuestión de la legitimidad de la ley, como la construcción de posicionamientos identitarios abiertos a la diferencia y la alteridad.

Las ideas que a continuación se exponen tienen por principal objetivo, establecer las coordenadas teóricas que, al interior de la obra de Freud, permiten apuntalar estos señalamientos, con el objeto de profundizar en los alcances de estas consideraciones frente a problemáticas sociopolíticas contemporáneas como la naturalización de las identidades y las formas ordinarias de violencia que se ejercen sobre grupos e individuos en situación de exclusión.

La argumentación posee dos partes: i) La vida pulsional y los horizontes políticos del psicoanálisis, y ii) Aproximaciones psicoanalíticas a lo político: identidad, violencia y exclusión. En el primer título, se abordan dos pasajes de la obra de Freud, que se consideran de importancia para pensar el problema psíquico de la inconvertibilidad de la violencia: los apartados 6 y 12 del Plan general del Proyecto de Psicología (1895), titulados “El dolor” y “La vivencia del dolor”, y, Duelo y Melancolía (1917). Posteriormente, se intenta demostrar cómo la intuición del espacio psíquico que permite el posicionamiento del sujeto frente al dolor y el sufrimiento, abre las puertas a la problemática del goce, lo irrepresentable y, en definitiva, a la negatividad y al diferimiento del empuje pulsional que sostiene el proceso de sublimación. La segunda parte del artículo busca desarrollar una discusión psicoanalítica sobre el actual escenario sociopolítico. Con este objeto, en primer lugar, se abordan las reflexiones que Freud realizara en el contexto de la primera guerra mundial (1914-1918), De guerra y muerte. Debates de actualidad (1915), respecto de los componentes psicológicos que subyacen al sentimiento de desilusión. Posteriormente, la argumentación se centra en problemáticas políticas y sociales contemporáneas concernientes a la radicalización de las identidades, las retóricas comunitarias y los escenarios de exclusión. Esta reflexión busca contraponer las actuales formas de naturalización de las identidades y los procesos psíquicos e intersubjetivos que permiten la construcción de un espacio de historización y diferimiento frente a los nuevos desafíos planteados por las violencias contemporáneas. 


\section{Primera parte:}

\section{La vida pulsional y los horizontes políticos del psicoanálisis}

En el Proyecto de psicología científica (1895), el problema que plantea la cuestión del dolor para la intelección de un aparato psíquico organizado por la exigencia de descarga, promueve la necesidad de pensar la incapacidad de las inhibiciones psíquicas respecto de los estímulos que provocan dolor. Esta incapacidad, sin embargo, no refiere en modo alguno al colapso de la organización psíquica, puesto que, al contrario, promueve la construcción de facilitaciones aún más expeditas para la descarga. Así, para Freud, las modalidades con que el psiquismo humano hace frente a la cuestión del dolor, vendrán a ser demostrativas de un arquetipo normal desde el cual pensar lo patológico. Las ideas que expone Freud sobre la vivencia del dolor, introducen el recuerdo del dolor como una imagen mnémica cuya investidura genera una respuesta correspondiente a la vivencia genuina del dolor, en virtud de lo cual, se desprende el afecto de displacer asociado. Por consecuencia, la particularidad del dolor, consistirá en que el esfuerzo del psiquismo tenderá a una desinclinación de la investidura de la imagen mnémica hostil, constituyendo, por tanto, el prototipo de todas las acciones de defensa, con las que el psiquismo intenta el desalojo de los recuerdos hostiles.

Ahora bien, dentro de este esquema, las facilitaciones que suscitan la inhibición de la descarga, sientan las bases de los procesos de discernir-pensar que permiten alejar la respuesta del organismo de una simple reacción tendiente a la des-investidura de las huellas mnémicas hostiles. En este proceso, el papel que cumplirá la imagen del prójimo, que tiene la cualidad para Freud de constituirse para lo psíquico como primer objeto-satisfacción y primer objeto-hostil, será el de condicionar el discernimiento humano a la intervención del lenguaje que permite el encuentro con el semejante, a la vez, que sienta las bases de la distinción entre lo idéntico y lo diferente, mediante el uso de los signos lingüísticos. Desde este punto de vista, sería posible inferir, que, en el marco de esta reflexión, el efecto civilizatorio que introduce el lenguaje en el psiquismo humano, proyecta sobre el espacio de las relaciones interpsíquicas las mismas mediaciones entre el impulso-inhibición, acción y pensamiento, que organizan el espacio intrapsíquico.

Dentro de la obra de Freud, la expresión más clara de esta lógica de relaciones, que replica en la constelación intrapsíquica las modalidades de vinculación con los semejantes, 
se encuentra en los desarrollos que ligan las expresiones melancólicas y de la manía, con el narcisismo. En Duelo y melancolía (1917), Freud reconocerá en las modalidades de vinculación con los objetos de amor, específicamente en la identificación narcisista al objeto amado, la condición que suscita el empobrecimiento yoico frente a los requerimientos, injurias y hostigamientos provenientes de las instancias psíquicas críticas del yo. El establecimiento del conflicto en estas coordenadas gatillaría no solamente la reemergencia de posiciones libidinales narcisistas, sino también la ambivalencia y el sadismo que caracterizan a estos vínculos eróticos. Como expresa Freud, será la satisfacción de las tendencias sádicas y de odio vueltas sobre la propia persona, aquello que movilizará los dinamismos psíquicos hasta alcanzar las graves perturbaciones afectivas presentes en estos cuadros clínicos.

El dolor que genera la pérdida del objeto amado, y que en el caso del doliente demanda un importante trabajo de contrainvestidura tendiente a reconocer tramo por tramo de la realidad la inexistencia del objeto en el mundo exterior, en la melancolía, avanza hasta vaciar el propio yo. Así, en los cuadros melancólicos, el trabajo psíquico que permite evitar la investidura de las huellas mnémicas del dolor, se ve complejizado por la ligadura narcisística hacia el objeto, la cual, empobrece la vivencia psíquica, tornándola vacía y monocorde. El complejo melancólico, como lo remarca Freud, se comporta como una herida abierta, que atrae sobre sí, desde todas partes energías de investiduras.

Cabe resaltar dos derivaciones que surgen de la contraposición entre los primeros desarrollos freudianos sobre la cuestión del dolor y los avances teóricos que Freud presenta a partir del estudio de la melancolía. En primer lugar, a diferencia de la defensa normal frente a la investidura de huellas mnémicas del dolor - que aspira a forzar el desalojo de las representaciones hostiles, en la melancolía, será el conjunto del psiquismo el que será puesto al servicio de una constante investidura de lo hostil, provocando, un afecto continuo de dolor. En segundo lugar, la afluencia de las investiduras psíquicas sobre los recuerdos hostiles, tendrá por fundamento los vínculos libidinales con el objeto. Será, pues, en definitiva, el carácter ambivalente y sádico de las identificaciones narcisistas, aquello que promoverá el vuelco del psiquismo sobre sí mismo, reactualizando en el espacio intrapsíquico los conflictos experimentados en el espacio interpsíquico.

No obstante, será en la reformulación de la teoría pulsional, en Más allá del principio del placer (1920), en donde es posible reconocer la intrincada relación que Freud atisba para 
estos complejos intersubjetivos y la problemática que el sufrimiento y el dolor instalan para el aparato psíquico. Freud observará que la exigencia que se expresa a través de los afectos de dolor o del sufrimiento psíquico, no es sólo aquella que ha intuido en la tendencia a mantener un estado de investidura psíquico mediante el cual responder frente a los estímulos hostiles - lo que aseguraría el reconocimiento de un espacio de ligadura psíquica para el manejo de estos estímulos y la convertibilidad de la violencia-, sino también la tendencia a cero de la descarga. Es decir, la tendencia a repetir el estado de inercia originario, anterior a toda perturbación por las fuerzas de la vida.

Es importante resaltar que la elucidación del talante de las fuerzas pulsionales, representado por las pulsiones de muerte, introduce también una significativa distinción respecto de las posiciones freudianas sobre el masoquismo. Éste dejará de ser sólo la expresión de una reinversión sobre el yo de la agresividad primeramente dirigida al objeto, para representar la tendencia del psiquismo humano a mantener la tensión (y no sólo su descarga). Como explica Freud, El problema económico del masoquismo (1924), el masoquismo sería a la vez un relicto y un testigo, de las primeras ligaduras entre las pulsiones de vida y de muerte, de forma tal que la tendencia humana a la destrucción, el apoderamiento y la violencia dirigida a otros, sería en principio, expresión de los esfuerzos del psiquismo humano por proyectar en el espacio exterior, en las relaciones interpsíquicas con otros, la tendencia a la descarga y al aumento de la tensión, que al inicio de la vida conflictuaba el propio ser. Otra faceta de esta conflictividad, se haría presente para Freud, en lo que denominó masoquismo moral, en el que se manifestaría la lógica de las relaciones que el yo establece con el superyó, y a través de éste, con las instancias ideales introyectadas por el yo y con el conjunto de disposiciones transmitidas por la cultura. Por consiguiente, la reinversión del sadismo hacia la propia persona es el resultado de las diversas transacciones y juegos de fuerza que el sujeto va estableciendo a partir de la sofocación cultural de las pulsiones, de suerte que, la vivencia psíquica que se expresa como masoquismo moral, será el resultado colateral de los esfuerzos del sujeto por reprimir la agresividad que puede dirigir a otros, la cual será acogida al interior del superyó, potenciando su agresividad. Así, la necesidad de castigo frente a las exigencias del superyó, es capaz de poner de relieve las tensiones internas de un sujeto en contradicción con sus propios impulsos. Es decir, de un sujeto que frente a la hostilidad de la violencia, no puede sino redoblar el impasse de las disposiciones psíquicas tendientes a la construcción de un espacio para la convertibilidad 
de ésta, introduciendo una fracción de lo indecible que se expresa como sufrimiento propio y del otro, pero que lo encamina hacia una violencia situada en los orígenes mismos del psiquismo y del vínculo social.

Los desarrollos de Freud, en Psicología del yo y análisis de las masas (1921), permiten introducir nuevas luces sobre los postulados psicoanalíticos sobre la violencia y la lógica de relaciones que el sujeto establece respecto de las instancias psíquicas ideales y el superyó. Las líneas dedicadas por Freud al análisis de las masas, ponen de manifiesto el empobrecimiento de los procesos psicológicos, tanto conscientes como inconscientes, que ponen freno a las pulsiones más primitivas. Este empobrecimiento de la vida psíquica suspende todas las adquisiciones que ha forjado el trabajo de la cultura en los individuos. De suerte que, la masa, puntualiza Freud, abraza lo imposible, el pensamiento por imágenes, al modo de los procesos oníricos que no conocen la incerteza.

La sugestionabilidad de la masa respecto de las indicaciones del líder, será el factor determinante en la elucidación de estos fenómenos. Así, ajena a todo diferimiento pulsional, la masa actúa según una completa complacencia respecto de sí y del ideal representado por el líder. De hecho, de acuerdo a los análisis desarrollados por Freud, estas características de las masas, tendrían por fundamento una ligadura narcisística al líder, mediante la cual el objeto es puesto en el lugar del Ideal-del-yo. Será, pues, la idealización del objeto de amor, el mecanismo psíquico operante detrás de la irracionalidad y de la violencia presentes en los fenómenos de masas. Este mecanismo, cabe subrayarlo, tendrá como fuente las disposiciones infantiles del narcisismo y, por tanto, movilizará la ambivalencia frente al otro y al vínculo social. De esta forma, el vaciamiento de la vida psíquica a favor de las disposiciones narcisísticas y el empuje pulsional, se instala como un aspecto central en la dilucidación de la aproximación psicoanalítica a la violencia.

Por otra parte, la ausencia o la debilidad de las mediaciones subjetivas que permiten introducir la dialéctica de la palabra, frente a los requerimientos que abrigan las aspiraciones de la masa, sitúa al individuo como una mera reacción frente a dispositivos ideales y las disposiciones agresivas constitutivas del psiquismo. Dejando ver que, desde el punto de vista de los procesos de elaboración del impulso agresivo, la apelación a un orden exterior al individuo (la patria, la raza, la tradición) no se vincula necesariamente con la apertura del sujeto a las mediaciones culturales frente a la vida pulsional. Al contrario, como lo observa Freud, en estos relatos imaginarios que buscan resaltar las pequeñas diferencias, el origen o 
el destino de los pueblos, anida la violencia y la agresividad frente al otro, por lo que, resultan ser, una vía aún más expedita para la expresión de estas manifestaciones.

Cabe resaltar, no obstante, que el trabajo de la sublimación se establece como una contracorriente frente a estas disposiciones. Como lo indica Sophie de Mijolla-Mellor (2009), el desarrollo de la teoría del narcisismo y la delimitación de las nociones de Idealdel-yo y Yo-ideal, permite a Freud introducir la diferenciación entre idealización y sublimación, a partir del reconocimiento tanto del horizonte y amplitud de los procesos sublimatorios, como de los efectos que éstos ejercen sobre el sujeto. En este marco, la idealización representa un fenómeno parcial dentro del cual el objeto es modificado por la investidura libidinal que provoca su exaltación por parte del sujeto, pero no la transformación del sujeto en su dinámica pulsional. A la inversa, dentro del proceso sublimatorio, la distancia que se establece entre el yo y el Ideal-del-yo, admite la creación de un proyecto para el sujeto. En el espacio subjetivo de la sublimación, por tanto, el sujeto se aleja de la ilusión de alcanzar un estado sin conflictos, dando lugar al duelo de los anclajes narcisistas de la infancia. Así, sería posible inferir que los mecanismos sublimatorios, estarían sostenidos por una suerte de identificación del sujeto a la dimensión de la falta, la cual propiciaría un impulso constante a la simbolización, permitiendo religar al sujeto a las ganancias culturales de su comunidad, al tiempo que permite la construcción de una distancia temporal y efectiva entre el sujeto y los valores movilizados por los discursos sociales.

La lectura del análisis de Mijolla-Mellor, en consecuencia, admite situar como eje del proceso sublimatorio, el establecimiento de una apertura, dinámica, del sujeto sobre sí mismo, la que suscita un movimiento constante de subjetivación a partir del impulso siempre renovado de las exigencias pulsionales. Siendo posible indicar en este sentido, que los procesos sublimatorios constituyen, por sí mismos, una respuesta frente a la ferocidad del superyó y el masoquismo moral, situándose, al contrario, en el espacio de simbolización abierto por la articulación del sujeto a su naturaleza significante y pulsional. Por consiguiente, a diferencia de un simple acto de descarga o de la repetición de determinadas facilitaciones psíquicas, el espacio de la sublimación conduce a la renovación de un tiempo y un espacio, cuyas coordenadas meramente lógicas, restituyen el re-encuentro del sujeto, el significante y la falta. 
Será al interior de estas coordenadas psíquicas inconscientes que son admisibles los procesos sublimatorios, con los que el sujeto puede fundamentar y construir una posición ética respecto del otro y las restricciones impuestas por la vida colectiva. Como lo observa Lacan (1973), comprender la dimensión ética del sujeto, requiere de reconocer el movimiento acéfalo de la pulsión, como un impulso tendiente a simbolizar la falta de lo real dentro de la experiencia del sujeto, más allá de las costumbres y de las instituciones culturales. De suerte que, es en el esfuerzo por sobrepasar el horizonte de los objetos especulares, en donde el sujeto, inserto en el devenir histórico de las figuras ideales constitutivas del universo simbólico, está en posición de sobrepasar las ilusiones prometidas por las instancias ideales y exigidas por la moral social, forjando un posicionamiento ético frente a la Ley y la violencia.

\section{Segunda parte:}

\section{Aproximaciones psicoanalíticas a lo político: identidad, violencia y exclusión}

\section{Mediaciones psicoanalíticas frente al problema de la legitimidad y la desilusión}

Las observaciones que Freud realizara, en De guerra y muerte. Debates de actualidad (1915), a propósito de la legitimidad de la violencia, permiten ponderar la posición de las mediaciones psicoanalíticas frente al problema que la violencia política introduce para el discernimiento de las relaciones entre el sujeto y las colectividades. El estado de incertidumbre y desorientación provocado por la guerra, representa, así lo visualiza Freud, una reacción frente a la desilusión suscitada por los efectos de la guerra sobre las ganancias civilizatorias de la cultura. Así, frente al declive de los valores de la civilización y las aspiraciones morales requeridas para los individuos por los ideales culturales imperantes, la actitud adoptada no será otra que la de aferrarse a la desilusión como a un relicto de una historia mayor, que prometía a los individuos civilizados reconocerse insertos en un espacio social sin conflictos. Esta actitud psicológica frente a la guerra, sin embargo, descansaría para Freud, en una denegación de la agresividad y de la violencia siempre subyacente al psiquismo y a los vínculos interhumanos. La agresividad y la violencia denegada y enmascarada psicológicamente como desilusión, se trasmutaría en un especial modo de 
sugestionabilidad frente a los requerimientos de los Estados en disputa, los que no cesarán de demandar para los individuos, los mayores sacrificios.

La legitimidad de la violencia, cuyo monopolio y ejecución es autoproclamada por y para los Estados, es avalada por la pérdida de la mayoridad de parte de los individuos. La idea de mayoridad, poco frecuente y de uso predominantemente legal, refiere a la capacidad de los individuos de ejercer su posición y derechos civiles y políticos, siendo, por consecuencia, su pérdida, la antesala del tutelaje y la dependencia. Los mecanismos de censura, de desinformación y la persecución de la disidencia, son puestos de relieve por Freud, como el prototipo de la imposición del poder de los Estados sobre los individuos, que, en tiempos de guerra, ven así reforzada su sugestionabilidad frente al orden institucional. De suerte que, el Estado, supuesto garante de la civilidad, adquiriere el carácter imperativo y persecutor de las formaciones del superyó, en su modo más cruel y primitivo.

Freud finaliza estas observaciones sobre la desilusión, abordando la ambivalencia del individuo y la masa frente a estos anclajes, que en definitiva adquieren su poderío de las fuerzas inconscientes y los refugios narcisísticos a los que se abrazan los individuos. Será, pues, en este espacio de mediaciones imaginarias, en donde se entremezclarán las aspiraciones sádicas y el temor frente al propio sufrimiento y la propia muerte. Por tanto, la ambigüedad de estos posicionamientos subjetivos frente a la guerra y la muerte, la hallaríamos finalmente en la íntima comunión entre las aspiraciones de dominio y control del orden institucional y la preocupación constante del individuo respecto de su propia integridad. De forma tal que, bajo estas coordenadas, el individuo reafirma su convicción de ser partícipe de un colectivo mayor: el mundo civilizado. Ilusión, a partir de la cual el sujeto proyecta su propia contingencia en beneficio de la historia extendida de sus ancestros y su comunidad. Así, a la inversa de una corriente representativa de los esfuerzos del sujeto por sublimar la violencia pulsional, los mecanismos psíquicos subyacentes al sentimiento psicológico de desilusión, se refugian en objetos imaginarios, producen el empobrecimiento de las producciones de los pueblos, de un modo similar a los mecanismos psíquicos que, en los cuadros melancólicos, vacían de sentido la vida de los individuos. 


\section{Formas de la agresividad en el mundo contemporáneo: radicalización de las identidades colectivas y nuevas formas de violencia}

La ligazón vislumbrada por Freud, entre los sentimientos de desilusión, inseguridad personal y el refugio del individuo en las narraciones colectivas de grandeza, adquiere en el actual orden político y social una relevancia incuestionable y particularmente visible en contextos en donde se ponen en cuestión los grandes dramas humanos y sociales de la contemporaneidad. A saber, las repercusiones subjetivas, comunitarias y sociales causadas por los desplazamientos forzados, las guerras identitarias, la exclusión y la conflictividad social.

En este contexto, como es posible inferir a partir del trabajo de diversos autores (BRUNO, 2007; CREPÓN, 2014; FASSIN, 2002; GEISSER, 2018; TUCCI, 2016), la particularidad que posee la cuestión de la alteridad en el actual escenario político y social, se halla en la apelación a la inseguridad de las propias fronteras identitarias frente a procesos en donde lo otro se confunde con lo propio. De hecho, esta situación de permeabilidad interna es puesta de relieve en los continuos exámenes que las sociedades contemporáneas hacen de su propia identidad, frente a otros individuos con quienes se comparte o se podría compartir la ciudadanía política, pero no la pertenencia cultural o racial. En este sentido, tanto la conformación como la administración de estos discursos nacionalistas contemporáneos, es puesta en marcha mediante la apelación a una retórica identitaria que, sobrepasando los límites estrictamente políticos y geográficos de los Estados, representa, en cambio, un imaginario de fronteras y límites, portador de márgenes cuya transgresión es percibida rápidamente como expresión del ultraje y de la violencia. Se asiste en la actualidad, por tanto, a la coexistencia de una ideología de la mundialización (AUGÉ, 2009) — que invita a imaginar un mundo sin fronteras - y al recrudecimiento de estas lógicas identitarias, expresivas de una cartografía política fragmentada, dividida; arraigada en sentimientos primitivos de inseguridad y hostilidad (THIBIERGE, 2007, 2007; SCIARA, 2007).

Se podría considerar: las formas contemporáneas de construcción de las identidades comunitarias, no adquieren su fundamento, o al menos no solamente, en una hipotética reconstrucción y reafirmación de la identidad nacional. No se trata solo de un retorno a los idearios nacionalistas que dieron luz a las grandes guerras del siglo XX, sino en la puesta en marcha de una lógica identitaria que se interroga de manera continua por los límites de lo considerado participe de la propia historia y destino. Dicho de otra forma, si la identidad 
no está representada por los límites políticos de una nación, se hace necesaria la recuperación o creación constante de fragmentos identitarios, que operen como un ideal convocante para los sujetos destinatarios de estos enunciados y retóricas.

Pues bien, si se avanzara en esta interpretación, sería posible reconocer algunas expresiones de lo inconvertible de la violencia presentes en las sociedades contemporáneas:

Una faceta de estos problemas políticos y sociales contemporáneos, se encontraría en los efectos psicológicos, intersubjetivos y sociales, de los procesos de exclusión. Numerosos son los análisis de los fenómenos de violencia que remarcan los efectos que sobre las comunidades, grupos e individuos, posee la aceleración y profundización de estas lógicas modernas de la violencia (BAUMAN, 1999; DUFOUR, 2003; OGILVIE, 2012). Lógicas que serían capaces de expresar la ruptura de los vínculos humanos que introduce el capitalismo, en su modo de expresión actual, el cual tendría la potencialidad de producir individuos que, adoleciendo de formas simbólicas y sociales de inserción al vínculo social, devienen en último término, desechables. Por tanto, en estas violencias contemporáneas, el sujeto se confronta a su propia destrucción, o, en otros términos, a la imposibilidad de su representación e institución. Se podría inferir que la agresividad del sujeto enfrentado a estos fenómenos sociales y culturales, se vuelca sobre sí mismo y se expresa como incertidumbre frente a una historia cargada de vacíos en la significación producto de la precariedad de los resortes simbólicos que la constituyen. Se asistiría, en este plano, a la producción imaginaria de un sentimiento de pertenencia que pregona la identificación del sujeto sino a un lugar — puesto que radican en espacios de exclusión—, sí a una identidad perdida o prometida. Este rostro de la agresividad, se podría decir, es el de la impotencia. En el polo opuesto, sería posible emplazar una forma de agresividad asociada a la ilusión de pertenencia a un conjunto de enunciados que se encuentran al margen del tiempo y del discurrir histórico. Esta expresión de la agresividad permitiría, en tanto que refugio identificatorio, sobrellevar la profunda conflictividad de las tensiones sociales contemporáneas mediante la construcción de una imagen de sí a partir de la del otro: extranjero, migrante, enemigo. A través de la cual, no pocas veces, se disimularía una importante precariedad material y simbólica, expresiva de los profundos desvalimientos que padecen muchos de los individuos convocados por estos discursos, que finalmente definen su rostro, desde el autoritarismo más arcaico. 


\section{Conclusión}

Si se aceptan las apreciaciones expuestas en el presente artículo, sería posible reconocer que la expresión contemporánea de las tendencias agresivas, permite reconocer una búsqueda individual y colectiva de circuitos referenciales que se amparan en ideales y enunciados de índole imaginario. De suerte que serían demostrativos, de la apelación a un orden discursivo que busca naturalizar las identidades, situándolas al margen de los procesos históricos y de los procesos de apropiación subjetiva. Como ya se ha establecido, al interior de la obra de Freud, la denegación de las mediaciones culturales que permiten el diferimiento de la violencia, confiere las condiciones para una expresión más intensa y expedita de la violencia y las tendencias agresivas. En efecto, como ya se puntualizó a propósito de los procesos sublimatorios, el surgimiento de las posiciones éticas del sujeto psicoanalítico, no refieren en modo alguno a la sola sobrevaloración de objetos o fragmentos identitarios idealizados. Al contrario, estos procesos deben comprometer la transformación dinámica del sujeto, abriendo un espacio de convertibilidad no del otro - en cuanto esto supondría la asimilación de la alteridad-, sino más bien, de la construcción de un espacio psíquico que propicie la convertibilidad de la propia agresividad al interior de las coordenadas intersubjetivas que busquen la legitimación de los horizontes culturales de pertenencia, mediante un movimiento de historización y subjetivación, a la vez, individual y colectivo.

Punto de vista desde el cual, sería posible sino comprender, al menos atisbar, la raíz profunda de la angustia que despierta el otro en los actuales contextos sociopolíticos, caracterizados por importantes mutaciones en los modos de simbolizar la pertenencia identitaria. Esta angustia, remite ciertamente a las dificultades presentes en los actuales escenarios sociopolíticos, sin embargo, igualmente, retrotrae la angustia primitiva del sujeto frente a la construcción de los espacios de delimitación y elaboración que dieron origen a los primitivos esbozos del yo (Je) (CASTORIADIS, 2002). De suerte que se puede señalar, que la angustia que despiertan las actuales figuras políticas y sociales de la alteridad —el migrante, el exiliado, el enemigo, el otro-, integran: i) las vivencias de angustia originaria, es decir, las primeras diferenciaciones que dieron luz al espacio psíquico representacional frente al mundo pulsional y la apremiante necesidad del otro, ii) las ligazones interpsíquicas de carácter narcisístico, que exponen la fragilidad del propio yo (Je) respecto de situaciones de peligro real (interno o externo), cuya expresión psíquica se corresponde con los 
sentimientos de amenaza, ultraje y de desamparo, en un mundo que padece de profundas inestabilidades identitarias, iii) la construcción social de un otro que permita reafirmar la propia identidad, construcción que como se ha indicado: posee el carácter de la apelación a un colectivo impermeable a las modificación histórica de las sociedades, o bien, adquiere los contornos de una identidad impotente frente a su propia significación, a causa de la producción en masa de sectores que se ven excluidos y en dificultades de ser instituidos por el horizonte político-social contemporáneo.

Si se admiten estos análisis, sería posible indicar, por último, que la propuesta que desarrollara Freud frente al problema asociado a la inconvertibilidad de la agresividad y la violencia, consiste en apuntar que será desde un trabajo propiamente ficcional, opuesto al impulso por reencontrar lo idéntico — bajo sus diversas figuras, como identidad de percepción, identidad narcisística, identidad de los pueblos, las naciones o las civilizaciones-, en donde los individuos y las comunidades políticas, estarían en condiciones de impulsar una verdadera política de lo contingente, dispuesta a reconocer en sí misma, el carácter transformador de una constante crítica a la legitimidad de sus propios fundamentos.

\section{Bibliografía}

AUGÉ, M. Pour une anthropologie de la mobilité. Payot, 2009.

BAUMAN, Z. La globalización. Consecuencias humanas. Fondo de Cultura, 1999

BRUNO, A. S. Les identités nationales à l'épreuve de la décolonisation et de la migration. Revue française des affaires sociales, n. 2, p. 113-135, 2007.

CASTORIADIS, C. Sujet et vérité dans le monde social-bistorique. Paris: Seuil, 2002

CREPÓN, M. Le crédit de l'europe. Rue Descartes, n. 3, p. 39-42, 2014.

DUFOUR, D. R. L'art de réduire les têtes: sur la nouvelle servitude de l'homme libéré, à l'ère du capitalisme total. Paris: Denoël, 2003.

FASSIN, D. L'invention française de la discrimination. Revue française de science politique, v. 52, n. 4, p. 403-423, 2002.

FREUD, S. Proyecto de psicología. In: STRACHEY, J. (Ed.) y ETCHEVERRY, J. L. (Trad.). Obras completas: Sigmund Freud (V ol. I). Amorrortu. (Trabajo original publicado en 1950 [1895]), 1978. 
FREUD, S. De guerra y muerte. Debates de actualidad. In: STRACHEY, J. (Ed.) y ETCHEVERRY, J. L. (Trad.). Obras completas: Sigmund Freud (Vol. XIV). Amorrortu. (Trabajo original publicado en 1915), 1978.

FREUD, S. Duelo y Melancolía. In: STRACHEY, J. (Ed.) y ETCHEVERRY, J. L. (Trad.). Obras completas: Sigmund Freud (Vol. XIV). Amorrortu. (Trabajo original publicado en 1917), 1978.

FREUD, S. Más allá del principio del placer. In: STRACHEY, J. (Ed.) y ETCHEVERRY, J. L. (Trad.). Obras completas: Sigmund Freud (Vol. XVIII). Amorrortu. (Trabajo original publicado en 1920), 1978.

FREUD, S. Psicología de las masas y análisis del yo. In STRACHEY, J. (Ed.) y ETCHEVERRY, J. L. (Trad.). Obras completas: Sigmund Freud (Vol. XVIII). Amorrortu. (Trabajo original publicado en 1921), 1978.

FREUD, S. El problema económico del masoquismo. In STRACHEY, J. (Ed.) y ETCHEVERRY, J. L. (Trad.). Obras completas: Sigmund Freud (Vol. XIX). Amorrortu. (Trabajo original publicado en 1924), 1978.

GEISSER, V. Projet de loi sur l'asile et l'immigration: indignation morale versus cynisme gouvernemental? Migrations Société, n. 1, p. 3-11, 2018.

LACAN, J. Le séminaire. Livre XI. Les quatre concepts fondamentaux de la psychanalyse. Paris: Seuil, 1973. (Trabajo original publicado en 1964).

OGILVIE, B. Violence et représentation. In: Ogilvie, L'bomme jetable. Essai sur l'exterminisme et la violence extrême (pp. 59-85). Paris, France: Éditions Amsterdam, 2012.

SCIARA, L. Les lieux de ségrégation constituent-ils la pointe avancée de la clinique contemporaine? Journal français de psychiatrie, n. 1, p. 35-38, 2007.

MIJOLLA-MELLOR, S. Le choix de la sublimation. Paris: Presses Universitaires de France, 2009.

THIBIERGE, S. Objet actuel de la psychologie de masses. Journal français de psychiatrie, n. 28, p. 2426, 2007.

THIBIERGE, S. Clinique de l'identité. Paris: Presses Universitaires de France, 2007

TUCCI, I. L'accueil et l'intégration des migrants en Allemagne : les limites de l'hospitalité et de la solidarité. Migrations Société, v. 166, n. 4, p. 15-35, 2016.

RECIBIDO: 03/12/2018

RECEIVED: $12 / 03 / 2018$

APROBADO: 19/07/2019

APPROVED: 07/19/2019 